\section{Visual Analog Scale}

Tamara Bushnik

Director of Inter-Hospital Research and

Knowledge Translation, Rusk Rehabilitation,

New York, NY, USA

\section{Synonyms}

VAS

\section{Definition}

Visual analog scale (VAS) is a method of measuring a subjective construct believed to exist along a continuum. VAS typically takes the form of a straight line of a specific length, usually $100 \mathrm{~mm}$, with extreme descriptors at either end. Individuals rate the characteristic or attitude of interest by placing a mark at a point somewhere along the line that represents their subjective experience. For example, a pain VAS could ask "in the past
7 days, how severe has your pain been?" with possible ratings from "no pain" to "very severe pain." Once the individual has placed a mark along the VAS continuum, the distance from one end of the line to the mark is measured and expressed in millimeters. This method has been used with aphasic individuals to obtain a measure of depression, with stylized "smiley" and "sad" faces at either end.

\section{Cross-References}

Response to Intervention

\section{References and Reading}

Stern, R. A., \& Bachman, D. L. (1991). Depressive symptoms following stroke. American Journal of Psychiatry, 148, 351-356.

Wewers, M. E., \& Lowe, N. K. (1990). A critical review of visual analogue scales in the measurement of clinical phenomena. Research in Nursing \& Health, 13, 227-236. 